\title{
Chinese Transfer in English Grammar Teaching
}

\author{
Kang Yinghua, \\ Department of Student Affairs, Chifeng University, 024000
}

\begin{abstract}
Chinese transfer plays an important role in the teaching and learning of English grammar. Though there are many differences between English and Chinese, many rules are shared by English and Chinese, especially in terms of grammar. Therefore, in teaching of English grammar, proper use of transfer of Chinese grammar may help the learners learn English. This paper introduces Chinese positive transfer and negative transfer in learning English grammar, and discusses how to make use of Chinese transfer to improve English teaching.
\end{abstract}

Keywords- English grammar; Chinese transfer; positive transfer; negative transfer

\section{INTRODUCTION}

Transfer refers to the process to make use of the knowledge and experience mastered before to help master new knowledge in learning, including positive transfer and negative transfer. Chinese language, as a nonintellectual factor, plays a crucial role in leaning English grammar. Since most English learners have poor English proficiency but rich Chinese knowledge, using Chinese grammar in learning English grammar can support the learning. Thanks to a lot of rules shared by English grammar and Chinese grammar, combining the both via a correct approach will train the learner's grammar awareness and lay a solid foundation for applying English in practice.

\section{Chinese transfer in English grammar learning}

\subsection{Positive transfer of Chinese}

Though being mentioned long ago, positive transfer of Chinese has not attracted enough attention, and thus has not been extensively applied in English grammar teaching. The positive transfer of native language originates from the process that the learner understands English. In the process, comprehension is the first link-the comprehension of target language reflects the learner's knowledge of native language, intelligence, ability and experience. A solid foundation of native language facilitates learning target language. Moreover, there is some relation between the level of one's native language and the level of his target language: the students who are good at native language usually do well in foreign language learning, indicating a positive transfer of native language in learning foreign language.

(1) Positive transfer in terms of grammar analysis

Chinese is an analytic language, and there are two main analytic methods: one is central-word based analysis, or analysis of members of sentences, used to analyze the role of each member of the sentence; the other is analytic hierarchy process, that is, to divide Chinese grammar into different layers like character, word, sentence and compound sentence and analyze each layer. 
In terms of the development course, English is in the transition from synthetic language to analytic language. More and more grammar adopts analysis (e.g. comparatives and superlatives of adjectives, such as interesting, more interesting, and most interesting). In this respect, English and Chinese tend to be more similar.

\section{(2) Positive transfer in terms of words}

In Chinese, according to their role in the sentence, the words can be categorized into noun, verb, adjective, status word, distinguishing word, numeral, quantifier, adverb, preposition, conjunction, auxiliary word, modal particle, interjection and onomatopoeia. In English, the words can be categorized into noun, verb, adjective, numeral, adverb, preposition, conjunction, interjection and determiner. The categorization standards used in the two languages are the same, and the categories are similar. Thus, teachers can compare the both languages in explanation to bring about good effects.

\section{(3) Positive transfer in terms of clauses}

In Chinese, sentences are divided into simple sentences and compound sentences: the former includes two parts (subject and predicate) and the latter is a complex sentence consisting of two or more simple sentences through a certain logical relationship. In English, the simple sentence in Chinese is called clause and the compound one is called sentence.

\section{(4) Positive transfer in terms of sentences}

The sentences in Chinese can be divided into combined complex sentences, and compound sentences. In the combined complex sentences, the clauses are equal, like the parallel structures in English grammar. The parallel structures in English grammar are a sequence consisting of structures of relevant meanings and identical layer connected by coordinating conjunction or other coordinating method. In learning English grammar, students often forget to use conjunctions: For example, Lily is singing, Lucy is watching TV. If a student is asked to translate the sentence in Chinese, it may be "Therefore, teachers can remind students to pay attention to the similarity and difference of the two languages.

There are four basic sentence patterns in both English and Chinese: declarative, interrogative, exclamatory and imperative sentences. If one masters the sentence patterns in Chinese, he will masters those in English readily.

\subsection{Negative transfer of Chinese}

According to analysis, the negative transfer of Chinese in learning English grammar is due to that Chinese and English belong to different language families, and their words and sentences are different. So, in learning English grammar, Chinese rules will come out first, which will impair the learning of English, especially in morphology, syntax and expression.

(1) Negative transfer in terms of morphology

English is a "stress-timed" language, while Chinese is a syllable-timed one. The stress of polysyllabic English words causes great difficulties to many students' word spelling because of the negative transfer of Chinese: many errors are related to silent letters, as well as weak syllables or vowels. Therefore, teachers should instruct students to master correct articulation and pronunciation rules in teaching. In addition, students are apt to 
make mistakes in respect of nouns, articles, prepositions and parts of speech. For example, the nouns can be divided into countable and non-countable ones and the plural and singular forms, which cannot be found in Chinese. So there is no reference in learning, and teachers should remind students to keep an eye on the difference between the Chinese words and English ones, and encourage them to read more, so to enhance the sense of language and reduce the negative transfer of Chinese.

\section{(2) Negative transfer in terms of syntax}

In Chinese, the sentence functions relying on semantic structure, of which the word order is an important factor. On the other hand, in English, the sentence function relies on the word form and the combination of sentences, and the role of word order is not as important as that in Chinese. The reversed order of modifiers and their modified term is common, and inversion will not change the function of a sentence. In English, the sentence with the form of "there be", inverted sentence, question, attributive clause and compound sentence are typical sentence patterns, which increase some difficulties for students to study English grammar due to their specialty. The transformation of sentence pattern that can be found in English does not exist in Chinese. Taking the attributive clause as an example, in Chinese, the relation of a modifier and its central word is "modifier + central word", so the modifier is on the left, but in English, the attribute clause is on the right of the central word, which leads to high error rates in attribute clauses in learning. For example: [She wears a (red) coat]. (the attribute " (red)" is on the left of the central word "(coat)"). This is the third time. (The attribute clause "that they have met" is on the right of the central word). To overcome the negative transfer of
Chinese syntax, the above mentioned difference should be analyzed, to enhance students' awareness of English syntax.

\section{Inspiration of Chinese Transfer in English Grammar Teaching}

First, pay attention simultaneous use of Chinese and English in the teaching of English grammar, compare Chinese grammar and English grammar, and remind the learners to pay attention to the transfer of language, to improve their comprehension, promote positive transfer and reduce negative transfer of Chinese grammar. Second, provide the learner with training opportunities to input language timely, as the opportunities to use English, as well as grammar lessons, are less than those of Chinese. Third, a reasonable situation should be established in exercise: certain tasks ensures the involvement of students in exercise, and situational teaching can strengthen their awareness of discourse situation and improve their ability to choose sentences fit for the situation, which will guide the students to pay attention to how situation determines the choice of language forms. Fourth, teachers may present some interesting examples caused by differences of Chinese grammar from English grammar in the class, to enhance learners' memory of relevant knowledge and stimulate learning interest, and encourage learners not to fear mistakes, to overcome the fear and correct tech mistakes properly-through the correction, the learners will strengthen their understanding of relevant knowledge.

\section{Conclusion}

Based on the analysis above, it is concluded that Chinese grammar and English grammar have some similarities and differences. In learning English, the transfer of Chinese, including positive transfer and negative transfer, is evitable. In 
the teaching process, remind students to pay attention to the transfer of Chinese grammar in learning English grammar. Contrastive teaching should be employed properly to take advantage of positive transfer to increase leaning efficiency and avoid negative transfer, so as to improve effective learning of English grammar and turn the transfer of Chinese from an obstacle into a tool in learning English grammar.

\section{References}

[1] Huang Yong. Research on Transfer of Chinese Language in English Grammar Teaching in Middle School [D]. Wuhan University of Science and Technology, 2012.

[2] Liu Shuang. A Study on the Application of Language Transfer Theory to English Grammar Teaching [D]. Northwest
University, 2010.

[3] Xu Ping. A Study on the Influence of Chinese Negative Transfer to English Grammar Learning in Senior High School [D]. Liaoning Normal University, 2012.

[4] Wang Wenxiao. The Influence of Chinese Negative Transfer to English Grammar Learning in Senior High School [D]. Inner Mongolia Normal University, 2011.

[5] Li Lian, Shi Xiaohui. Application of Positive Transfer of Chinese Grammar in English Grammar Teaching [J]. Journal of Xianning University, 2010, (9).

[6] Bai Shuangye. Negative Transfer of Native Language and English Grammar Teaching in Junior High School [J]. School English, 2012, (8). 